\section{Intersections}

Canadian Journal of Music

Revue canadienne de musique
Intersections CANADIAN JOURAL OF MUSIO

\title{
Remembering a Dream: The Tragedy of Romantic Memory in the Modulatory Processes of Schubert's Sonata Forms
}

\section{Brian Black}

Volume 25, numéro 1-2, 2005

Northern Perspectives on Music and Culture

URI : https://id.erudit.org/iderudit/1013312ar

DOI : https://doi.org/10.7202/1013312ar

Aller au sommaire du numéro

Éditeur(s)

Canadian University Music Society / Société de musique des universités canadiennes

ISSN

1911-0146 (imprimé)

1918-512X (numérique)

Découvrir la revue

Citer cet article

Black, B. (2005). Remembering a Dream: The Tragedy of Romantic Memory in the Modulatory Processes of Schubert's Sonata Forms. Intersections, 25(1-2), 202-228. https://doi.org/10.7202/1013312ar
Résumé de l'article

L'idée du rêve comme besoin alternatif à la réalité imprègne plusieurs des sonates de Schubert. Ce " désir de ce qui n’a jamais été » constitue ce que Charles Rosen a identifié comme le tragique de la mémoire romantique. D’où les méthodes particulières de modulation utilisées par Schubert dans ses transitions, qui créent une impression séduisante, quoique évanescente dans le rapport tonalité/thème, un effet maintenu tout au long du mouvement, dont la progression suggère, en dernière analyse, la poursuite tragique d'une illusion.
Copyright @ C Canadian University Music Society / Société de musique des universités canadiennes, 2005
Ce document est protégé par la loi sur le droit d'auteur. L'utilisation des services d’Érudit (y compris la reproduction) est assujettie à sa politique d'utilisation que vous pouvez consulter en ligne.

https://apropos.erudit.org/fr/usagers/politique-dutilisation/ 


\title{
Remembering a Dream: The Tragedy of Romantic Memory in the Modulatory Processes of SCHUbERT's SONATA Forms
}

\author{
Brian Black
}

Yearning for an unattainable dream is a fundamental theme of early Romanticism. The object of longing may take various forms-from some dimly recalled state of union with nature to a more concrete sense of belonging in human society. ${ }^{1}$ The constant remembrance of this dream, which only aggravates the feelings of isolation and despair in the alienated artist, lies at the very heart of the tragedy of Romantic memory, so beautifully expressed by Charles Rosen (1995, 174-75):

The most signal triumphs of the Romantic portrayal of memory are not those which recall past happiness, but remembrances of those moments when future happiness still seemed possible, when hopes were not yet frustrated. There is no greater pain than to remember past happiness in a time of grief-but that is the Classical tradition of the tragedy of memory. Romantic memories are often those of absence, of that which never was.

In this instance, Rosen's comments are directed at Schubert's vocal music, specifically the song cycles Winterreise and Die schöne Müllerin. Yet the tragedy of Romantic memory colours Schubert's instrumental music as well. In fact, it permeates many of his most affecting works. ${ }^{2}$ How is it possible, though, for such a theme to be expressed in purely instrumental terms? In other words, how can

1 E.T.A. Hoffmann, for instance, identified "yearning for the infinite" as the quintessential characteristic of Romanticism in his famous essay on Beethoven's Fifth Symphony (Hoffmann, 1971). Yearning, specifically for a primal state of grace, also pervades such landmarks of Romanticism as Wordsworth's poem “Ode: Intimations of Immortality" (Wordsworth, 1974a) and Philipp Otto Runge's painting Morning from his unfinished cycle The Times of the Day, in which the new-born child opens out like a flower to the morning star in a dream-like dawn of golden yellows and pastel blues.

2 In his life, too, Schubert clearly identified with this theme, as can be seen not only in his deeply moving settings of such poems as Irrlicht and Der Lindenbaum, but also in the fable My Dream, which he wrote sometime in 1822. (For an interpretation of the first movement of the Piano Sonata in B-flat major, D. 960 through this tale, please see Peter Pesic [1999].) Perhaps the most touching evidence of how the tragedy of Romantic memory affected Schubert's life is found in his famous letter to Leopold Kupelwieser, written in March of 1824, after his recovery from the first onslaught of syphilis: "Imagine a man, I say, whose most brilliant hopes have perished, to whom the felicity of love and friendship have nothing to offer but pain.... Thus joyless and friendless I should pass my days, did not Schwind visit me now and again and turn on me a ray of those sweet days of the past." Quoted by Maurice J.E. Brown (1980, $42-43)$. 
a textless medium capture something as complex, yet as insubstantial, as the memory of "that which never was"-a vision twice removed from reality?

Some aspects of this question have been addressed recently by Susan McClary (1983), William Kinderman (1996) and Charles Fisk (2001), who have dealt separately with such issues as the choice of keys for secondary themes, thematic contrast and overarching tonal relationships. Unfortunately, a crucial aspect of the subject-the unusual character of Schubert's modulations-has only been touched on. The composer's highly individual handling of the modulatory process is one of the most striking features of his instrumental style. The effects of his innovations here may be felt in a wide variety of musical structures, but they emerge most forcefully in his sonata forms, where the manner in which the transition modulates often casts the subordinate key area as something illusory. In such cases, the listener encounters the dual idea of "dream"-both as a longed-for alternative to reality and as the literal act of dreaming, of being lifted out of corporeal existence. Furthermore, such transitions set in motion a series of events across the form, which, through audible reminiscences of this dreamlike state, ultimately capture the full tragedy of Romantic memory with all its feelings of alienation and unfulfilled yearning. Before turning to this aspect of Schubert's sonata form, though, it would be useful to look briefly at a texted work that is emblematic of the dream and of dreaming, his Lied Nacht und Träume, written in the summer of 1823 and published in 1825 as opus 42 , no. 2 . Here Schubert translates into music some of the most important literary components of the topic. The means by which he does so are particularly relevant to an interpretation of similar features in his instrumental music.

\section{Nacht und TräUme and the Musical Depiction of Dreaming}

The poem, by Matthäus von Collin, sets out the principal characteristics of dreams in Romantic literature, especially their involuntary quality, expressed here in their portrayal as unwilled gifts flowing from heaven into human hearts:

Heil'ge Nacht, du Sinkest wieder;

Nieder wallen auch die Träume,

Wie dein Mondlicht durch die Räume,

Durch den Menschen Stille Brust.

Die belauschen sie mit Lust

Rufen, wenn der Tag erwacht

Kehre wieder, holde Nacht!

Holde Träume, kehret wieder!
Holy night, you descend again;

Dreams also are flowing down,

Like your moonlight through space,

Into the quiet breast of mankind.

They observe them with delight

And call out when the day dawns

Come back, sweet night!

Sweet dreams, come back!

3 Walter Frisch, John Gingerich, John Daverio, Charles Fisk and Scott Burnham have all written on the topic of memory in Schubert's instrumental music in a recent issue of The Musical Quarterly (2000). The actual methods and significance of Schubert's modulatory process, however, do not figure prominently in these discussions, although other important issues are addressed. A particularly fine and thought-provoking treatment of the topic is found in Poundie Burstein's article dealing with tonic allusions in the subordinate key areas of Schubert's sonata forms and the sense of "memory or presentiment" these allusions evoke (Burstein, 2002). 
Musically Schubert has conveyed this involuntary quality by a sudden turn to the flat submediant chord, $G$ major, in bars 14 to 15 (example 1). There is no logical preparation of this event through G's applied dominant, merely a direct slip from the B-major to G-major chord. This completely unexpected move creates the sensation of being absorbed into an interior dream-world at that point in the poem where the dreamer pays rapt attention to the dream ("Die belauschen sie mit lust" [They observe them with delight]). Once G is reached, the music remains suspended in a tonally ambiguous space, occupied only by $G$ major and its subdominant $C$ major (bars 15-19). The otherworldly effect of the harmonic shift supports Susan McClary's contention that the early Romantics often imbued the flat submediant region with a dream-like atmosphere (McClary, 1983). This feeling is reinforced by the harmonic stillness of the prolongation of the $\mathrm{G}$ major chord, where for five bars the music focuses intensely on one harmony, elaborated solely by its own subdominant. While the framing passages in B major capture the calm of the night, they are still animated by harmonic movement. This movement virtually ceases in the central $\mathrm{G}$ major episode thus creating the effect of being lost in inner contemplation.

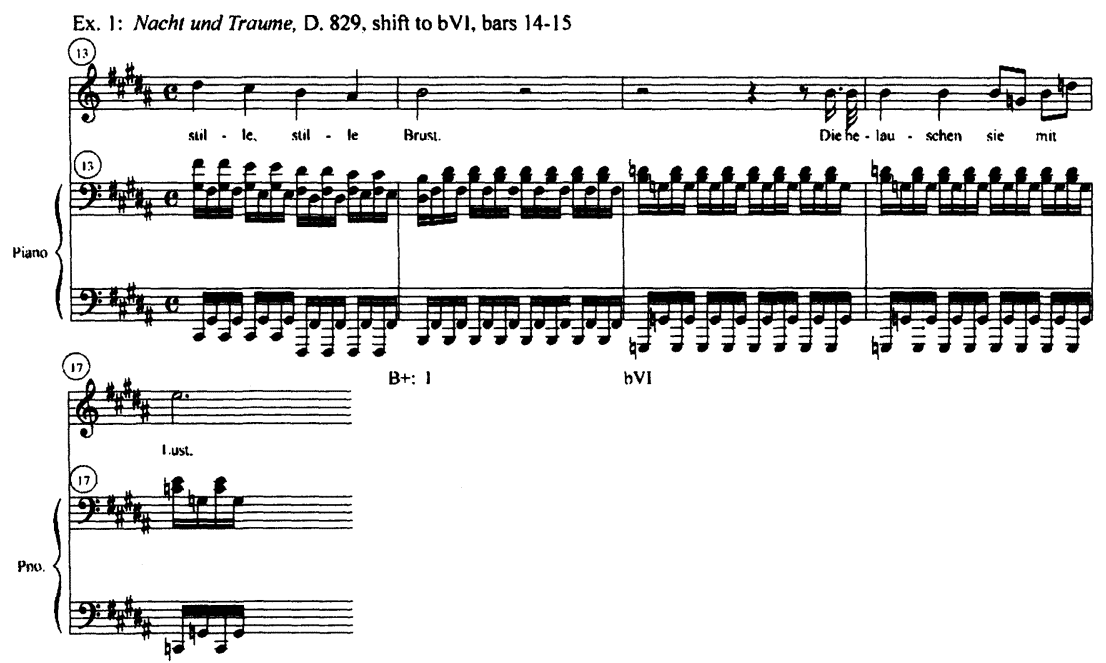

Example 1. Nacht und Traäume, D. 829, shift to bVI, bars 14-15

The return from this dream-state involves another important aspect of Schubert's art-his play on the different potential functions of a single pitch, in this case the altered sixth degree, G-natural and its enharmonic equivalent, F-double sharp. Quite often the flat submediant region will regain the tonic 
by the fall of flat six to five. Here, though, the flat six ascends to the normal sixth degree, G-sharp (example 2, bars 20-21). This is accomplished through the enharmonic ambivalence of the A-sharp diminished seventh chord (bar 20), whose G-natural becomes F-double sharp with the conversion of the diminished seventh to the applied dominant seventh of G-sharp minor (VI) in bar 21. The rising force inherent in the altered note's new leading-tone function expresses the yearning of "Kehre wieder heil'ge Nacht! Holde Träume Kehret wieder!" (Come back, sweet night! Sweet dreams, come back!).

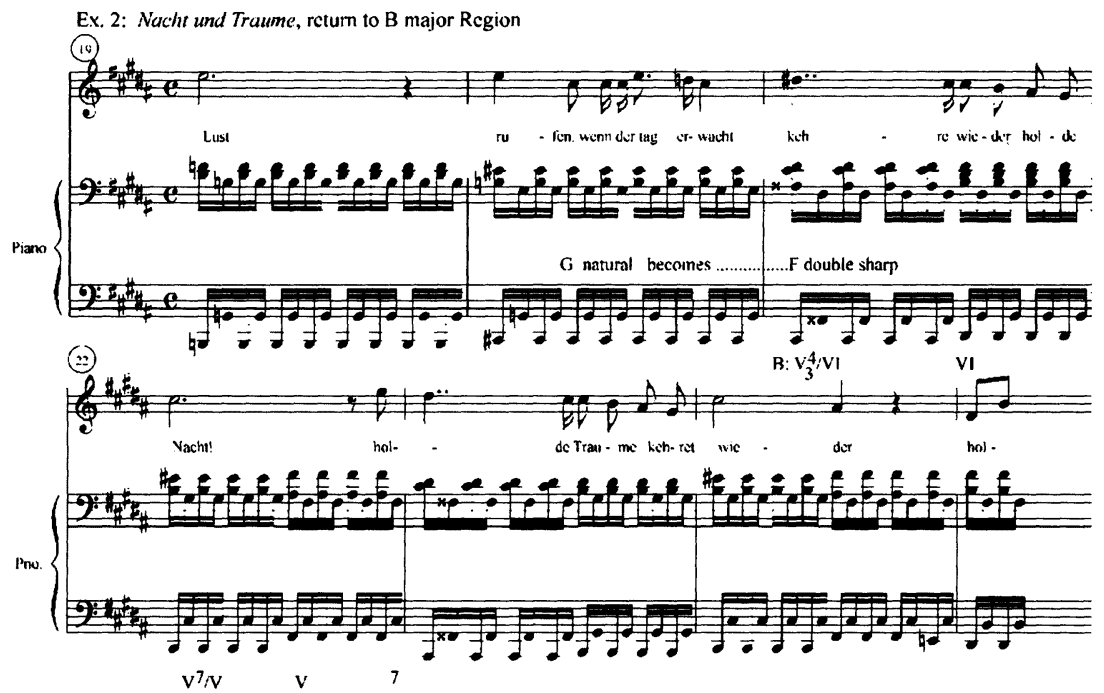

Example 2. Nacht und Träume, return to B major Region

The music that draws B major back from its dream-like digression to $G$, echoes the events immediately preceding the original diversion, specifically bars 8-14. In fact, the central excursion to $G$ major and its framing passages are all involved in the consistent enharmonic play on the affective significance of the G-natural/F-double sharp, whose changes in function give audible life to the shifting emotions of the text across the whole song. The first intimation of the poem's sense of yearning is heard in the F-double sharp of the piano's introduction, again as part of a tonicization of G-sharp minor (example 3a, bar 3). The F-double sharp is immediately answered by G-natural, which by falling to F-sharp in bar 4 suggests another important emotional element in the poem-regret. The F-double sharp-G-sharp motion returns in the first of the dream digression's framing passages, within a progression that ultimately tonicizes the dominant of B major (bars 8-11). Here the resultant sensation of desire colours the poem's first portrayal of dreams, as they glide down from heaven like moonlight ("Nieder wallen auch die Träume, wie dein Mondlicht 
durch die Räume" [Dreams also are floating down, like your moonlight through space]). Once again the F-double sharp is closely answered by G-natural, which this time suspends the listener in the breathless rapture of the dream-state itself (example 1, bars 15-19). The song then passes back through the yearning of the second framing passage (example 2, F-double sharp, bars 20-21) to end with the pangs of memory in the G-natural-F-sharp sighs of the piano's postlude (example 3b, bars 27-28). Thus Nacht und Träume concentrates the principal emotions associated with the dream-its rapture and its longing-within the varying meanings of one note. ${ }^{4}$
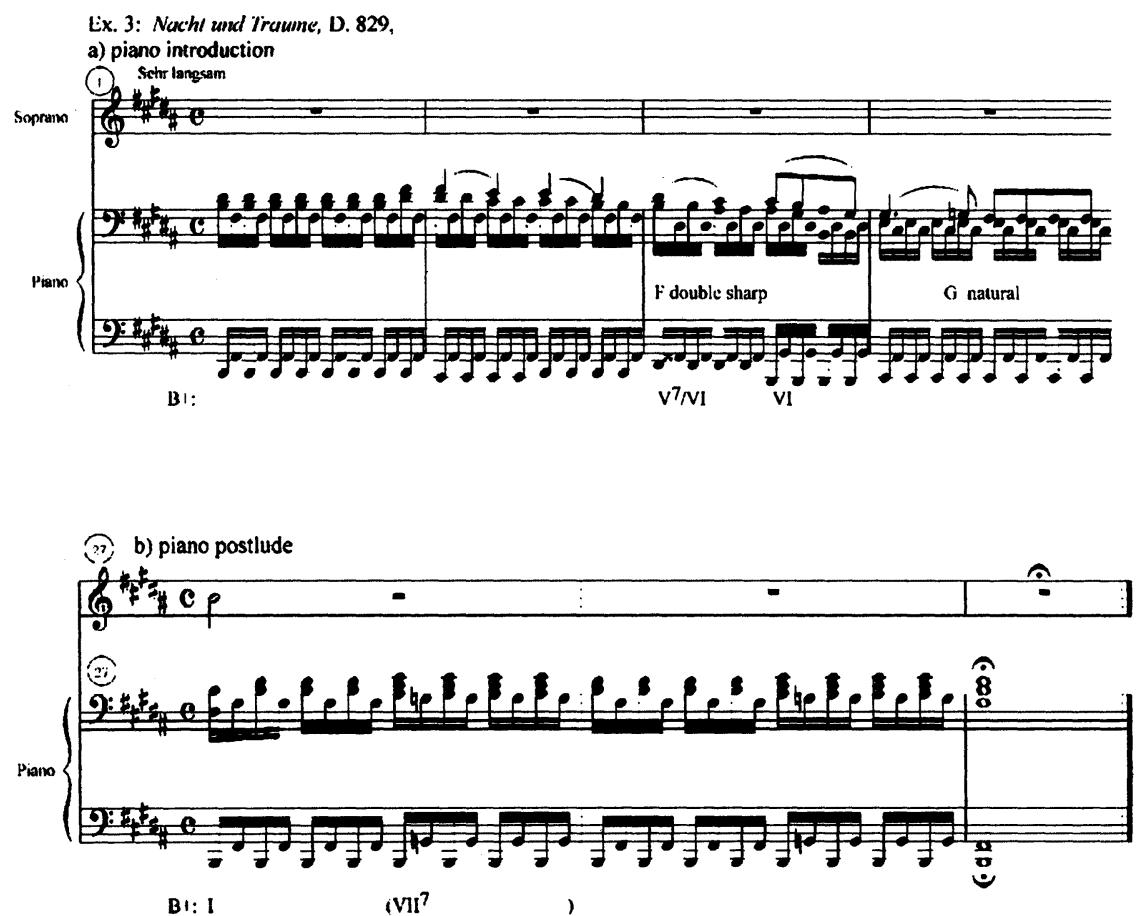

Example 3. Nacht und Träume, D. 829

4 Carl Schachter (1983) has also linked the portrayal of the dream in this song with the pervasive double meaning of the G-natural/F-double sharp. His association of the ephemeral nature of the G major dream state (bars 15-19) with the underlying function of the G-natural/F-double sharp as a chromatic passing tone is particularly eloquent. "The $\mathrm{G}$ major section crystallizes around a most transitory musical event-a chromatic passing tone. Yet, while we are immersed in it, it assumes the guise of that the most solid tonal structure, the major triad. Only at "wenn der Tag erwacht" does its insubstantiality become manifest; it vanishes, never to return except as an indistinct memory in the G-naturals of the coda." (75-76). 


\section{The Dream-like Qualities of Schubert's Transitional Process}

The visionary effect of Nacht und Träume's surprise shift to G major and the intricate web of allusion it spins from the various reinterpretations of one basic sonority are encountered on a broader level in Schubert's instrumental music. ${ }^{5}$ These two idiomatic features of his writing emerge most strikingly in the transitional schemes of his sonata forms, where they create a new atmosphere suggestive of "the dream" and its effects. The novelty of his approach here is best seen in a comparison of his practice with that of his Classical predecessors.

The Classical modulating transition invariably targets the new key's dominant harmony. ${ }^{6}$ In major-mode works, the new dominant chord is usually approached through its own applied dominant or an augmented sixth chord. ${ }^{7}$ In minor-mode works, the move to the dominant can be more abrupt and often dispenses with the applied chords. In both modes, the dominant, once reached, is usually prolonged as a preparation for the entrance of the new tonic at the beginning of the subordinate theme.

Certain characteristics arise from this process. There is a strong feeling of will, of striving for a goal, in the transition's progressive move towards its tonal destination. ${ }^{8}$ The steps of the process also generate a palpable logic. The winning of the new dominant and its subsequent prolongation act as a conventional sign of imminent tonal arrival, creating a feeling of expectation. It is the fulfilment of this expectation with the arrival of the new tonic at the beginning of the subordinate theme that brings to the scheme its strong sense

5 Quite often these reinterpretations involve the enharmonic double meaning of an altered tone, as with Nacht und Träume's G-natural/F-double sharp; but they can also rely upon the sudden transformation in function of a diatonic tone, as shall be seen in a number of the following examples. A detailed discussion of the reinterpretation of a single diatonic common tone as an important harmonic element in Schubert's music is provided by David Kopp in his work on chromatic third relations in nineteenth-century music (Kopp, 2002, chap. 2), while the significance of altered tones, particularly as predictors of modulations in Schubert's songs, is treated by Susannah Clark (2002, 231-38).

6 For two of the finest discussions of the Classical transition, including extensive examples, please see Charles Rosen (1980, chap. 9) and William Caplin (1998, chap. 9).

7 Rosen considers the preparation of the dominant chord of the new key by an applied chord an essential feature of the Classical transition's modulatory process. "Merely going to the dominant [key] and staying there will not work (with the minor mode, the move to the relative major is less problematic). What follows must still return to $\mathrm{V}$ of $\mathrm{V}$ and almost always $\mathrm{V}$ of $\mathrm{V}$ of $\mathrm{V}$ as well-at least if the music has any ambition." $(1980,236)$.

8 In minor-mode works, this dynamic character can be extreme, as in the gruff move to the dominant of E-flat major through its applied diminished seventh in the first movement of Beethoven's Fifth Symphony (bars 51-59). Equally powerful is the modulation to $\mathrm{E}$-flat major in the first movement of Mozart's Piano Sonata in C minor, K. 457, (bars 19-22). Here the explosive energy of the transition arises from a direct pivot on the tonic of $\mathrm{C}$ minor to the dominant of $\mathrm{E}$-flat major. The highly directed character of both of these examples lies at the opposite extreme to the floating effect of Schubert's modulations. 
of logic. This logic in turn is grounded in the tonal system's fundamental key-defining fifth relationship of the dominant to its tonic.

Rather than generating a progressive motion towards the new key, Schubert's transitions isolate the precise point of the modulation as a striking event. ${ }^{9}$ Often this moment has a certain visionary quality to it, appearing as a sudden revelation that colours the beginning of the subordinate theme itself. ${ }^{10}$ To accomplish this effect, Schubert cultivates the irrational in his modulatory schemes. The transition rarely signals its tonal goal through a careful preparation and prolongation of the new key's dominant. ${ }^{11}$ Quite the contrary, the transition's true destination is deliberately obscured until the very last second, creating a stronger emotional impact at the moment of the modulation through an intricately constructed surprise that thwarts the listener's expectations rather than fulfilling them. In many cases, the unexpected harmony is prolonged in order for its specific colour and momentary ambiguity to sink into the ear of the listener. As a result, all forward momentum is briefly suspended, thus intensifying the modulation's otherworldly character.

The schemes Schubert devises to generate the unusual effects of his modulations present a wide range of possibilities. At the most irrational extreme, the "wrong" dominant prepares the new key, as in the first movement of the String Quartet in G major, D. 887, composed in June of 1826 (example 4). Here the transition moves by sequence of descending perfect 4 ths from $G$ major to the dominant of B minor (bars 54-59). Once reached, the new dominant chord (F-sharp) is prolonged for six bars. These events, which suggest a straightforward, tonally focused transition, create the strong expectation of B minor as the key of the subordinate theme. What is more, this expectation is reinforced rhetorically by the transition's powerful dynamic curve, which moves in an uninterrupted crescendo from piano to fortissimo. The F-sharp dominant seventh, though, does not resolve to $\mathrm{B}$ minor at the beginning of the subordinate theme; instead it moves directly to the V4/2 of $D$ major-the true subordinate key-and it does so pianissimo. As in the slip to the flat submediant in Nacht und Träume, this surprise move, coupled with the sudden decrease in dynamics, creates the strange floating sensation of an escape into a private dream world. ${ }^{12}$

9 Hans Joachim Hinrichsen (1994) has discussed this particular trait of Schubert's transitions at some length.

10 The motivic relationship of the transition to the subordinate theme, specifically how it lends a specific "colour" to the theme and maintains that colour in the recapitulation, was first formulated by Klaus Rönnau (1982).

11 Avoidance of a dominant preparation here is a vital part of a carefully calculated plan and not the effect of Schubert's putative "aversion for the dominant" advanced by James Webster as one of the "inhibitions" affecting the composer's sonata forms $(1978,35)$. Signalling the music's goal through a clear dominant preparation would destroy the whole effect of the modulation and lend it an unwanted solidity.

12 The present case outlines a more elaborate version of Schubert's practice of approaching the new 

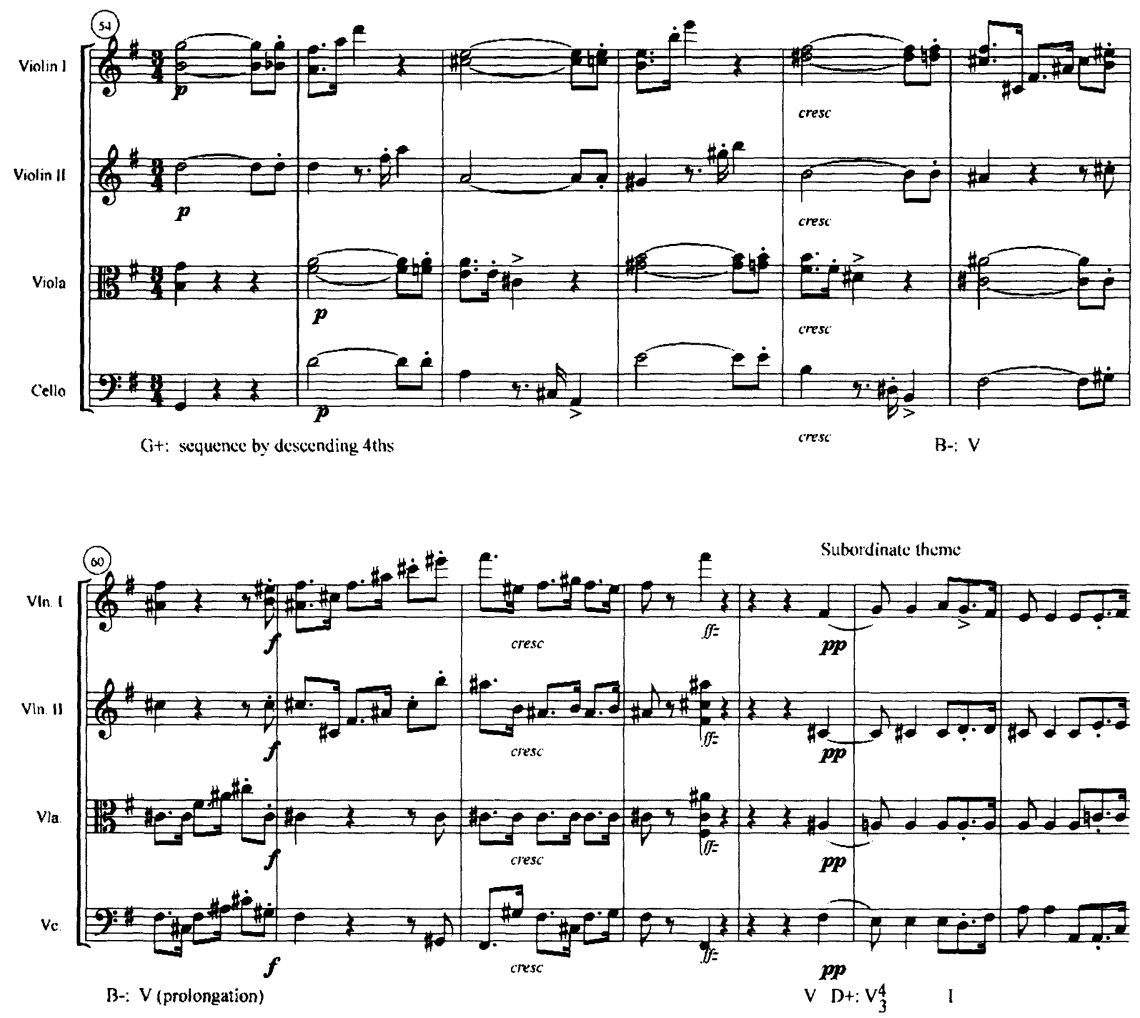

Example 4. String Quartet in G major, D. 88, i, transition 1

Even when Schubert's transitions do lead to the dominant of the new key, as in Classical practice, the dominant's arrival is itself a surprise. Furthermore, this chord is not usually the goal of a half cadence-the norm of Classical transitions-but rather the penultimate harmony of a perfect authentic cadence in the new key. The focus thus does not fall on the dominant chord but on the concluding tonic of the cadence, which often elides with the beginning of the subordinate theme. Consequently, the music is not allowed to reorient itself fully before the subordinate theme begins.

tonic through the dominant of the relative minor. In the G-major String Quartet, the false dominant moves to the true dominant seventh at the beginning of the subordinate theme-a gesture that becomes motivic in the movement. In other ploys, such as in the first movement of the String Quintet in C major, D. 956, or the first movement of the Piano Trio in B-flat major, D.898, the false dominant moves directly to the true tonic. This particular scheme has its origins in Classical practice, specifically the occasional use of V/VI as a dominant substitute to prepare the recapitulation at the end of the development section. See, for example, the first movement of Beethoven's Spring Sonata in F major, opus 24, bars 115-24. The effect here is very close to that of Schubert's modulatory feints. 
One of the most famous examples of this sort of ruse is found in the first movement of the Unfinished Symphony in B minor, D. 759 from October of 1822. The transition consists of merely four bars outlining a common-tone modulation from $B$ minor to $G$ major, in which the third degree of $B$ minor, $D$, is converted to the fifth degree of $G$ (example 5). The wonderful effect of the modulation, one of the most magical in Schubert's works, is achieved through the deliberate ambiguity of the sustained $D$, which floats for three bars in a rhythmically arrested state of tonal limbo. Its true function is only clarified at the very end of the fourth bar with the entrance of the dominant seventh of $G$ and the latter's immediate resolution to the $G$ chord, which initiates the subordinate theme. ${ }^{13}$ As in the G-major Quartet, the unexpected tonal deflection and the sudden decrease in dynamics for the move to the new key suggests a retreat into an interior world. ${ }^{14}$

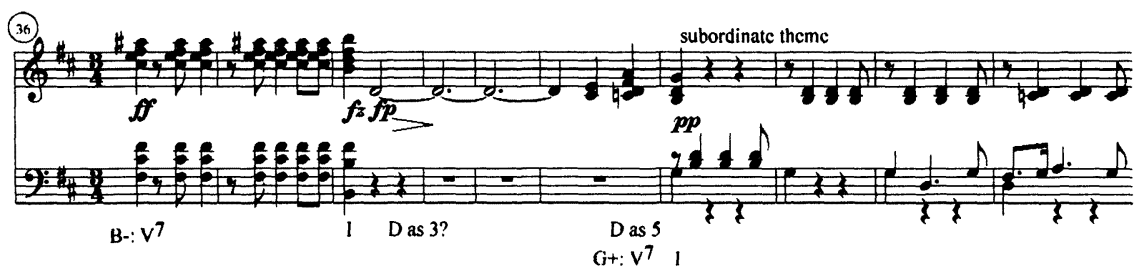

Example 5. Symphony in B minor, D. 759, "The Unfinished," $i$, transition

Even when Schubert follows the outlines of a more conventional transition, the point of modulation is still isolated as a heightened moment that affects the character of the ensuing subordinate theme. In the first movement of the String Quartet in A minor, D.804, for instance, the transition culminates in an orthodox dominant preparation of the subordinate key, $\mathrm{C}$ major (example 6). However, the path leading to the dominant and the nature of the modulation itself are unusual. The transition begins with a descending sequence of perfect fifths leading from $A$ eventually to $F$ (bars 44-49). When the F chord arrives in bar 49 , however, it functions immediately as VI in A. Thus the transition creates the impression of departing from the home key, but in reality circles back. The $\mathrm{F}$ chord, in turn leads through the French sixth to the

13 In this instance there is no question of the transition's cadencing directly into the subordinate theme; Schubert withholds an explicit cadential bass line in order to reinforce the floating character of the modulation. In most other transitions of this type, though, a perfect authentic cadential progression provides the harmonic framework for the modulation. Often a double cadence ploy is used, in which a cadential progression is initiated in one key, evaded, then set up again, only to be deflected into the subordinate key. There are numerous examples of this scheme across Schubert's career, from the first movement of the early Violin Sonatina in G minor, D. 383, through the first movement of the Trout Quintet, D.667, and, in a more elaborate form, the Piano Sonata in B-flat major, D. 960.

14 For an eloquent interpretation of the Unfinished Symphony see Fisk (2001, chap. 4). Here he refers to the arrival of the subordinate theme as the emergence of "a halcyon memory" (91). 
dominant of A (bars 50-51). This gesture is immediately repeated up an octave (bars 52-53), thus suggesting a dominant preparation for a full return to A minor. When the gesture is repeated once more, though (bars 54-55), the French sixth veers to the $\mathrm{I} 6$ of $\mathrm{C}$ major, not the expected dominant of $\mathrm{A}$. $\mathrm{C}$ is then prepared as the true subordinate key by the ensuing chord progression (I6-II6/5-V7).
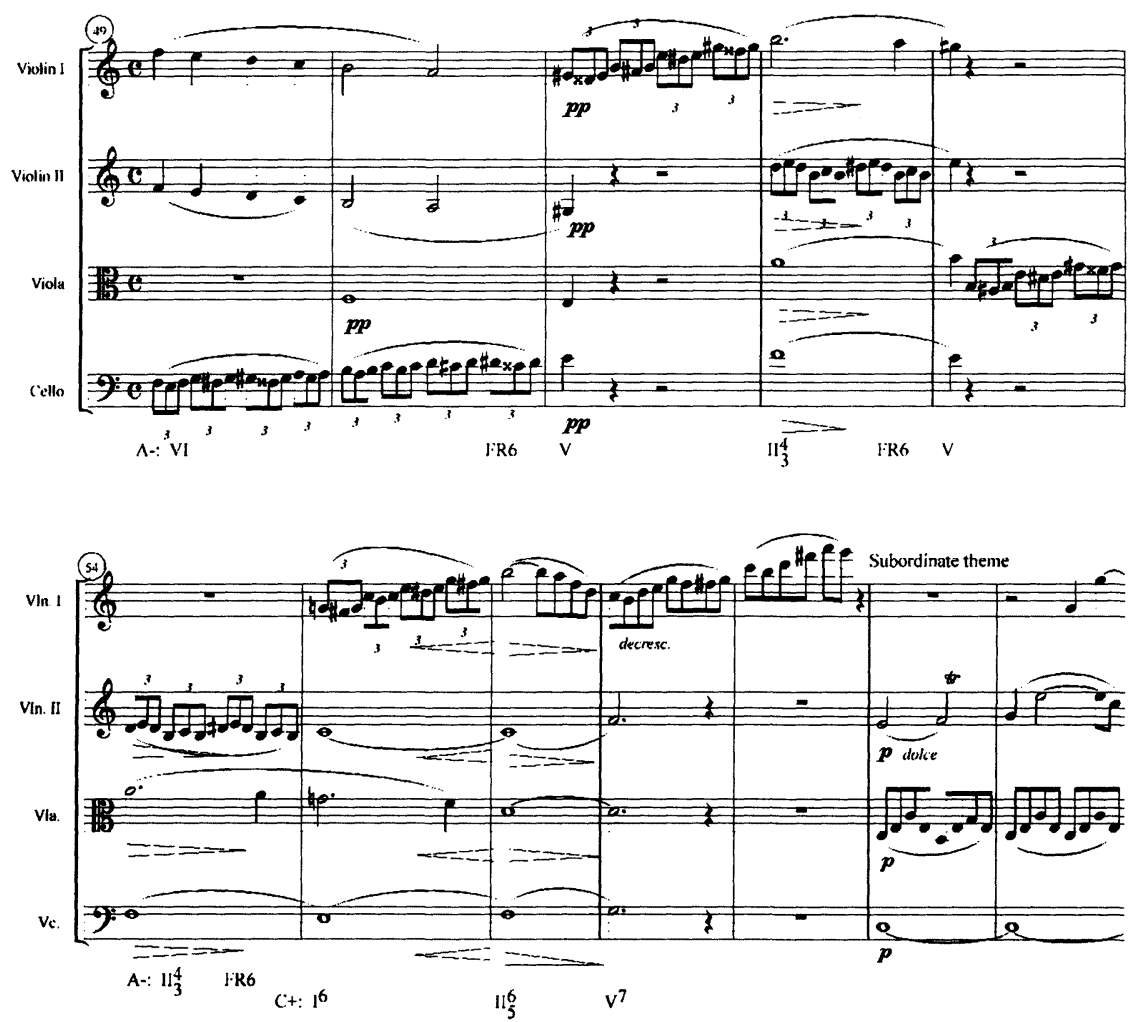

Example 6. String Quartet in A minor, D. 804, i., transition

The sudden deflection to $C$ major at bar 55 stands out as a marked event in the Quartet's modulatory process. At this particular point, the expectation of the dominant of $\mathrm{A}$, so carefully built up in the two preceding French six-to- $\mathrm{V}$ progressions, is thwarted by the intrusion of the $\mathrm{C}$ chord, which lifts the music unexpectedly into a new tonal realm. ${ }^{15}$ Thus Schubert transforms the repeated

15 As in the first movement of the Unfinished Symphony, the modulation is built upon a multivalent tone (here the $\mathrm{E}$ ) held in common between the two crucial harmonies of the surprise modulation-the $\mathrm{E}$ major dominant chord and the first inversion $\mathrm{C}$ major tonic chord. The move to the $\mathrm{C}$ major chord robs the bass note $E$ of its previous status as a dominant, leaving it in a momentary state of limbo (bar 55) until its new function is retrospectively defined by the arrival of the dominant of $\mathrm{C}$ major in bar 57. 
harmonic gesture through deliberate deception; and the striking nature of this transformation releases the tonic's hold in such a way as to create an entirely new atmosphere for the lyric intimacy of the subordinate theme. ${ }^{16}$

As a result of such feints in Schubert's transitions, the entrance of the subordinate key (and consequently its theme) often suggests an involuntary, illogical occurrence imbued with all of the mysterious intensity of a dream. This sense of an intrusion from beyond concrete reality is reinforced by what precedes the modulation: as in the A minor Quartet, there is often an apparent tonal impasse-an inability to progress past the tonic-which is only broken by the intervention of the surprise modulation. ${ }^{17}$ Furthermore, by not emphasizing, or even short-circuiting the key-defining elements of the tonal system (the tonic-dominant relationship), Schubert's unusual transitions can also undercut the solidity of the subordinate key, suggesting the insubstantiality of the dream's vision. This property of the surprise modulation plays an important role in Schubert's three-key expositions.

Here a distinction must be made between those three-key expositions where the initial subordinate key fades into the second subordinate key without ever being confirmed cadentially and those where both subordinate key regions are fully established and separated by a distinct modulating transition. ${ }^{18}$ In the first instance, the relative instability of the first key strengthens the modulation's suggestion of a fragile dream state, which is subordinated structurally to the more firmly grounded second tonal region. In the second instance, where both keys are cadentially confirmed, there is usually a clear differentiation in how each is approached: the modulation to the first subordinate key involves a tonal ruse, while the modulation to the second subordinate key is much more conventional and ends with a strong dominant preparation. This difference in the type of modulation implies that the first key is less solidly established than the second-a suggestion that is reinforced when, as often happens, the tonic re-emerges during the second transition, as if it had not been entirely dispelled by the initial modulation. ${ }^{19}$

16 Of particular importance in achieving the modulation's effect is the way in which the transfigured statement alters and yet echoes the outline of the previous gestures: instead of ascending from G-sharp through the $\mathrm{E}$ arpeggio to $\mathrm{B}$ over the cello's $\mathrm{E}-\mathrm{F}$ motion (bars 51-52), the first violin now rises to the same $B$, but from $G$-natural and through the $C$ arpeggio (bars 55-56).

17 Charles Fisk discusses this phenomenon in detail with respect to the first movement of the Unfinished Symphony (2001, 90-91). Susan McClary deals with a similar situation in the Impromptu in C minor, opus 90, no.1 (1983).

18 Examples of the first case include the first movements of the following works: the Symphony in C major, D. 944, The Great, the Piano Sonata in B-flat major, D. 960, the String Quintet in C major, D. 956. Examples of the second case include the Quartettsatz in C minor, D. 703 and the first movements of the String Quartet in D minor, D. 810, Death and the Maiden, and the Grand Duo Sonata for Piano, four hands, D. 812.

19 See Webster (1978, 30 and 35) for a discussion of this feature of Schubert's sonata forms. While his observations are accurate, I disagree with his conclusion that the re-emergence of the home key reveals another debilitating "inhibition" in Schubert's handling of the form - the reluctance to leave the tonic. As argued above, the special, often insubstantial character of the first modulation and the subsequent return through the tonic to the new key help to establish a carefully worked out tonal hierarchy in the exposition. 
What is more, the second subordinate key invariably assumes the role of the tonal pole to the tonic, in that it ends in strong cadential passages that are invariably restated in the tonic region in the recapitulation. ${ }^{20}$ Thus the first unusual modulation is projected against the second, more orthodox one in such a way as to reflect a carefully prepared difference in tonal weight and function between the two subordinate keys. ${ }^{21}$

The first movement of the String Quartet in D minor, Death and the Maiden, D. 810, which, along with the A-minor String Quartet, was composed in March of 1824 provides a good example of this pattern. Its exposition divides clearly into three tonal regions- $D$ minor for the main thematic group (bars 1-41), F major for the first subordinate theme (bars 61-83) and A major, then minor, for the second subordinate theme (bars 102-40). Each of the subordinate keys is prepared by a distinct transition and is confirmed by a concluding perfect authentic cadence. The first transition, leading from $D$ minor to $\mathrm{F}$ major (bars 41-60), follows a very strange path (example 7a): it quickly reaches the dominant ninth of A minor (bars 45-46) the second subordinate key, rather than F major, the transition's ultimate goal; it then turns back towards the tonic $\mathrm{D}$ minor, arriving at bar 50 on what promises to be a cadential $6 / 4$ in the home key.

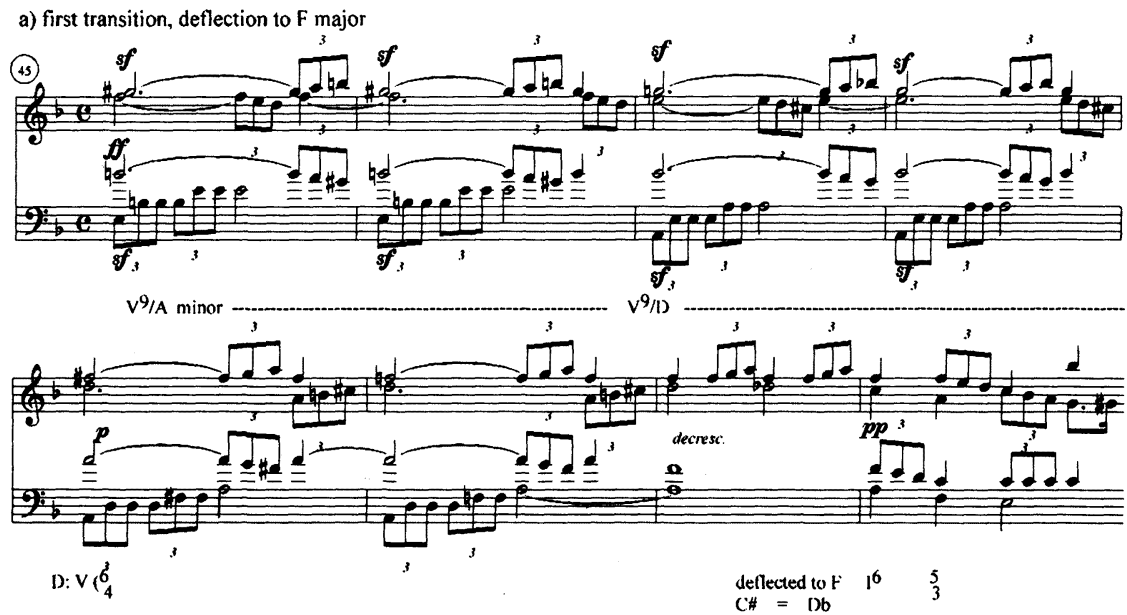

Example 7a. String Quartet in D minor, D. 810, "Death and the Maiden"

20 This situation is found in virtually all of Schubert's mature sonata forms of this type, including the Quartettsatz, D. 703. Here I disagree fundamentally with Hali Fieldman (2002), who has argued that the first subordinate key represents the true tonal pole to the home key, despite the fact that this region is never explicitly restated in the tonic, while the dominant area of the exposition is.

21 See Fisk $(2001,17-19)$ for a defence of the dominant as a structural key in Schubert's sonata forms and the deliberate tensions between the traditional structural background of the form and its unusual foreground events. 
The 6/4 chord, however, does not resolve to the home dominant, but instead is quietly transformed into a first inversion $\mathrm{F}$ major chord by the unexpected enharmonic resolution of C-sharp as D-flat to C (bar 51). This event in fact marks the precise moment of the shift from $\mathrm{D}$ minor to $\mathrm{F}$ major. Thus the first subordinate key emerges from a sudden tonal deflection rather than a carefully signaled modulation. As in the previous examples, this highly coloured change in key suggests an escape into an interior world, not only in the character of the enharmonic deflection itself but also in the dynamic curve leading up to the deflection, where the extreme tension of the initial dominant ninth in bar $\mathbf{4 5}$ is gradually released into the mysterious pianissimo arrival of the $\mathrm{F}$ major $6 / 3$ chord in bar 52 .

To some extent, the transition compensates for the unusual, premature arrival of $\mathrm{F}$ major during its course by ending with an apparently conventional dominant preparation for the new key (example 7b, bar 60). However, rather than solidifying $\mathrm{F}$ major, this gesture in fact subtly undermines it. The chord preparing the new dominant seventh, the applied diminished seventh of $\mathrm{C}$ (bar 59), is also the diminished seventh of A minor and was heard at the

b)

i) end of Ist transition and beginning of Ist subordinate theme
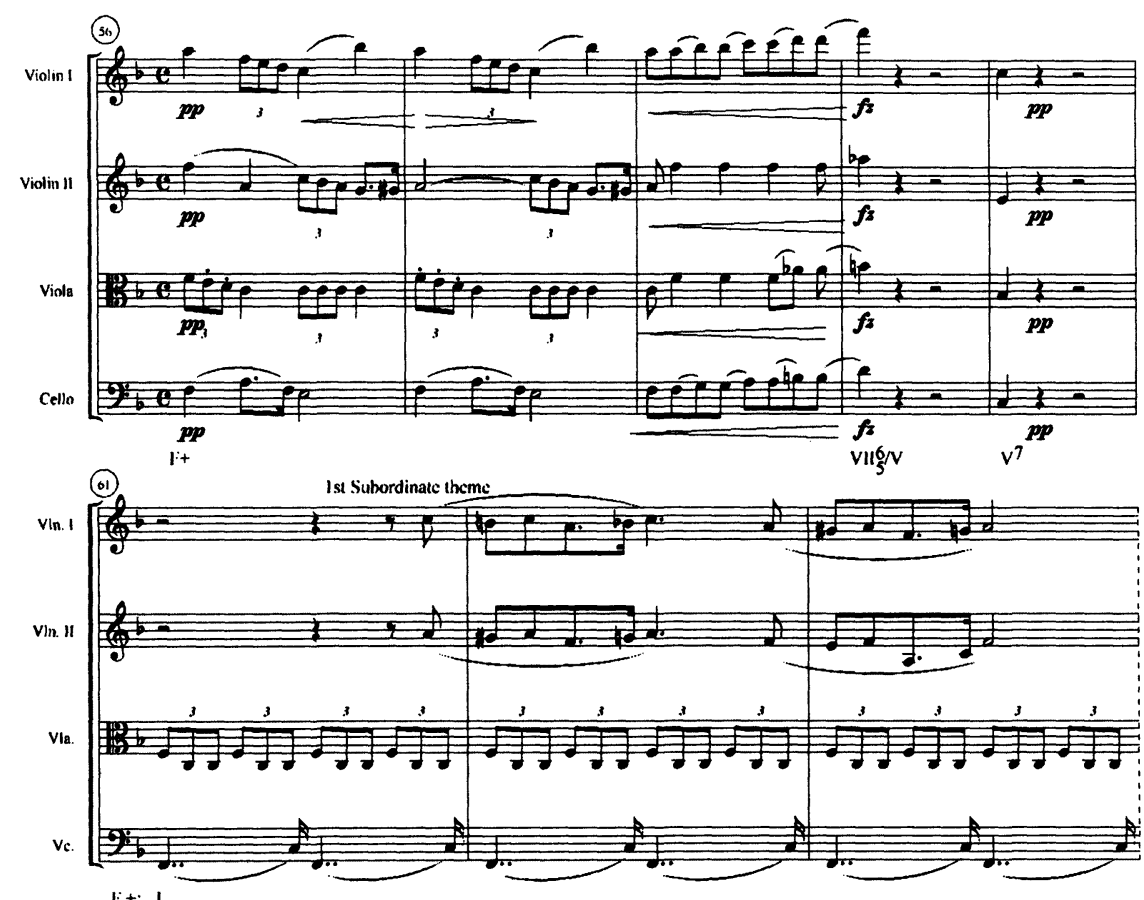

Example 7b1. String Quartet in D minor, D. 810, "Death and the Maiden" 
ii) Ist subordinate theme's latent VI - V motion in Aminor bb. $61-3$

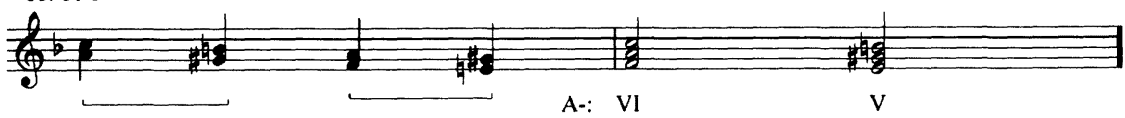

Example 7b2. String Quartet in D minor, D. 810, "Death and the Maiden"

beginning of the transition as the upper portion of the $\mathrm{E}$ dominant ninth (bar 45). The passage preceding the entrance of the applied diminished seventh plays with the enharmonic double of the chord's A-flat, the G-sharp, which consistently embellishes the A of the F major chord (bars 52-57, violin I and II). This melodic detail is then taken up as prominent feature of the ensuing subordinate theme, where both G-sharp and B-natural work in tandem as altered neighbour tones to A and $C$ (bars 62-63 etc.). Throughout the first subordinate theme, this neighbour-tone figure remains a purely melodic detail lending a certain A-minor colouring to the line. Latent within this figure is a VI-V harmonic motion in A minor (example 7b, ii), and it is precisely this progression that launches the modulation to $\mathrm{A}$ at the beginning of the second transition (example 7c). Here the G-sharp finally emerges as a true leading tone and $\mathrm{F}$ major loses its status as a tonic to become a subordinate harmony-the submediant-in A minor.

c) second transition

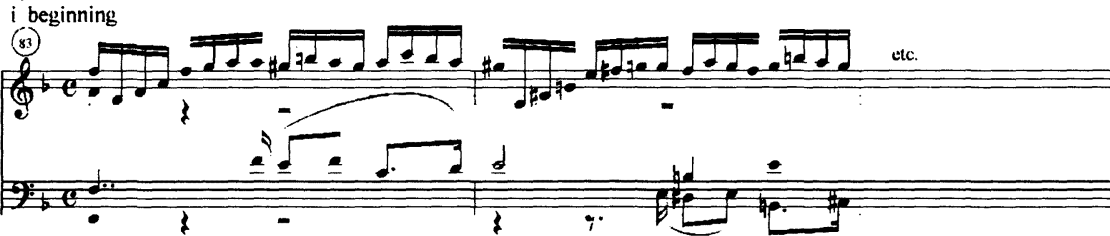

Iit: I

A-: VI
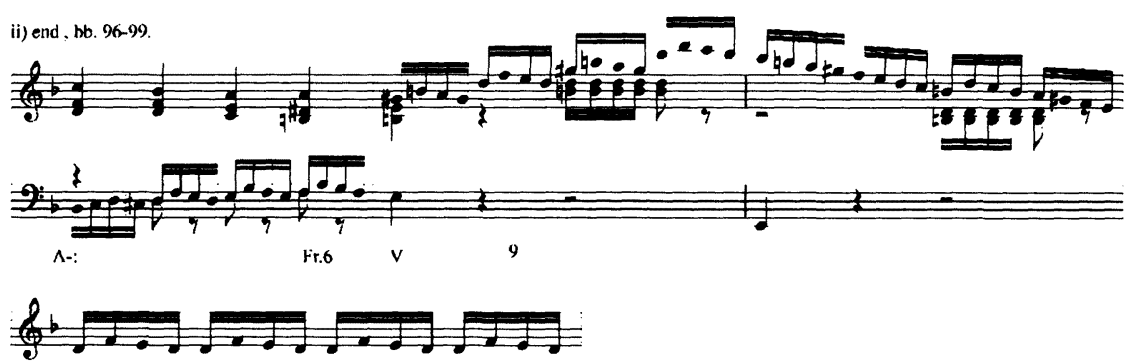

wc.

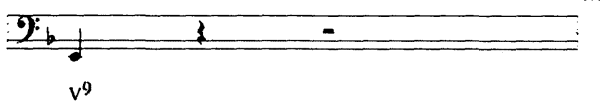

Example 7c. String Quartet in D minor, D. 810, "Death and the Maiden" 
Ultimately the second transition uses an intensified version of the VI-V progression to prepare the entrance of the second subordinate theme in $\mathrm{A}$ major/minor in bar 102. The actual progression consists of a move from the French sixth to the dominant ninth of A minor (example 7c, bars 97-100). Its concluding harmony is thus the very chord that figured so prominently at the outset of the first transition (bar 44). Essentially then the whole move into and out of the exposition's middle key, F, describes a circle, which comes back to its beginning (the $\mathrm{E}$ dominant ninth) as the entrance to the second subordinate key. The thematic and tonal region enclosed within the circle is undermined by both the striking, but less substantial, modulation to $\mathrm{F}$ major in the first transition and by the subsequent increasingly powerful predictions of A minor within the first subordinate theme. Projected as something transitory in relation to the exposition's tonal goal of A major/minor, F major thus assumes the character of a visionary digression that is finally dispelled when the framing $E$ dominant ninth returns at the end of the second transition to fulfil its "proper" function.22

The circular motion of the D-minor Quartet's modulatory process is not exceptional in Schubert's sonata forms; in fact it is a defining feature. Here the enharmonic reinterpretation that marked Nacht und Träume comes into its own as a major element in the composer's art of illusion. In order to achieve his tonal surprises, Schubert often relies upon the ambiguity of enharmonically multivalent chords, such as the diminished seventh with its four possible resolutions (already suggested in Nacht und Träume), or the German augmented sixth with its two. In many instances such enharmonic ploys provide the basis of the transition's modulatory scheme, which first familiarizes the listener with the normal resolution of the chord, then returns to the same chord only to veer off unexpectedly into the new tonality. ${ }^{23}$ The underlying strategy of such schemes thus depends upon a crucial aspect of the dream-the estrangement of the familiar-a topic we will discuss in more detail later. The audible parallels set up in the transition also create a spiral in the modulatory process, suggesting a limbo of circling memories. And this circling motion is not limited to the transition, but ripples outwards across the form in recurring reminiscences of key sonorities involved in the first modulation.

22 The tonal and harmonic relationships of the first movement of the D minor Quartet, D. 810, are much more complex than what has been touched on by this brief analysis. Of particular interest are the backward glances towards $\mathrm{F}$ major in the concluding cadential passages of the second subordinate theme (bar $114 \mathrm{ff}$ ). A full and detailed account of the movement, however, will form the core of a subsequent article on the functions of harmonic motives and their tonal references in Schubert's sonata forms.

23 See in particular the first movement of the early String Quartet in D major, D. 94, where the initial feint towards F-sharp minor, bars 26-36, is accomplished through the redirection of a diminished seventh chord which has been emphasized throughout the passages leading up to the deflection. A similar use of a multivalent diminished seventh chord for the mainspring of the transition's modulation is found in the Quartet Fragment in C minor, D. 103, and informs the transitional process of the first movement of the late Piano Sonata in B-flat major, D. 960. 
Taken together, the features of Schubert's transitional process we have discussed to this point provide a powerful vehicle for expressing the tragedy of Romantic memory. In order to see just how this is accomplished we must now look in some detail at the treatment of the affective and structural implications of Schubert's innovative modulatory process within a specific work. Here we turn to what is widely regarded as the first instrumental masterpiece of the composer's maturity, the Quartettsatz in C minor, D. 703, written in December 1820.

\section{The Tragedy of Romantic Memory in the Quartettsatz, D. 703}

This work is one of Schubert's most unusual sonata forms. ${ }^{24}$ The exposition, a three-key design, consists of a main theme in $\mathrm{C}$ minor, a first subordinate theme in A-flat major (VI), and a second subordinate theme in $\mathrm{G}$ major $(\mathrm{V})$. The form's most puzzling anomaly occurs at the beginning of the recapitulation, where the first subordinate theme enters in B-flat major (flat VII) ${ }^{25}$ The second subordinate theme follows more conventionally in $C$ major. A dramatic return of the main theme in $\mathrm{C}$ minor then closes off the movement. As shall be seen in the ensuing analysis, the unorthodox recapitulation, where neither the main theme nor tonic key returns, constitutes one part of a broader plan which, growing out of Schubert's idiosyncratic transitional process, strongly suggests the tragic yearning after a dream.

The emotional poles of this tragedy are established by the main and first subordinate themes. The extreme contrast in their characters exemplifies what William Kindermann has termed the tragic "dichotomy of external and internal experience-perception and imagination" in Schubert's music $(1996,65)$. The main theme builds to a despairing climax on the D-flat Neapolitan sixth (ex. 8, bars 9-10). The tension then gradually subsides culminating in a mysterious release into A-flat major and the otherworldly lyricism of the first subordinate theme (bars $27 \mathrm{f}$.).

The visionary effect of this modulation, which arises from one of Schubert's tonal surprises, depends upon parallels set up between the transition's concluding perfect authentic cadence in A-flat major (bars 23-27) and the two preceding cadences of the main theme in $C$ minor (bars 9-13 and 17-19). These parallels highlight two elements of the main theme's first cadence-the supporting bass motion F-G and the pre-dominant D-flat

24 It is so unusual, in fact, that a number of scholars have not accepted it as a sonata form. These include Webster $(1978,26)$ and Daniel Coren $(1970)$. Others, though, have treated it as essentially a sonata form, albeit an unorthodox one. See for instance Hinrichsen (1994, 135-37), Brian Newbould (1997, 350-52), and Fieldman, (2002). The precise formal designation of the Quartettsatz, though, is immaterial to the observations and arguments of the present article.

25 David Beach (1994) explains the move to B-flat major at this particular point of the form as part of the projection of the movement's chief motive, the descending $C-G$ tetrachord, onto a deeper structural level. 

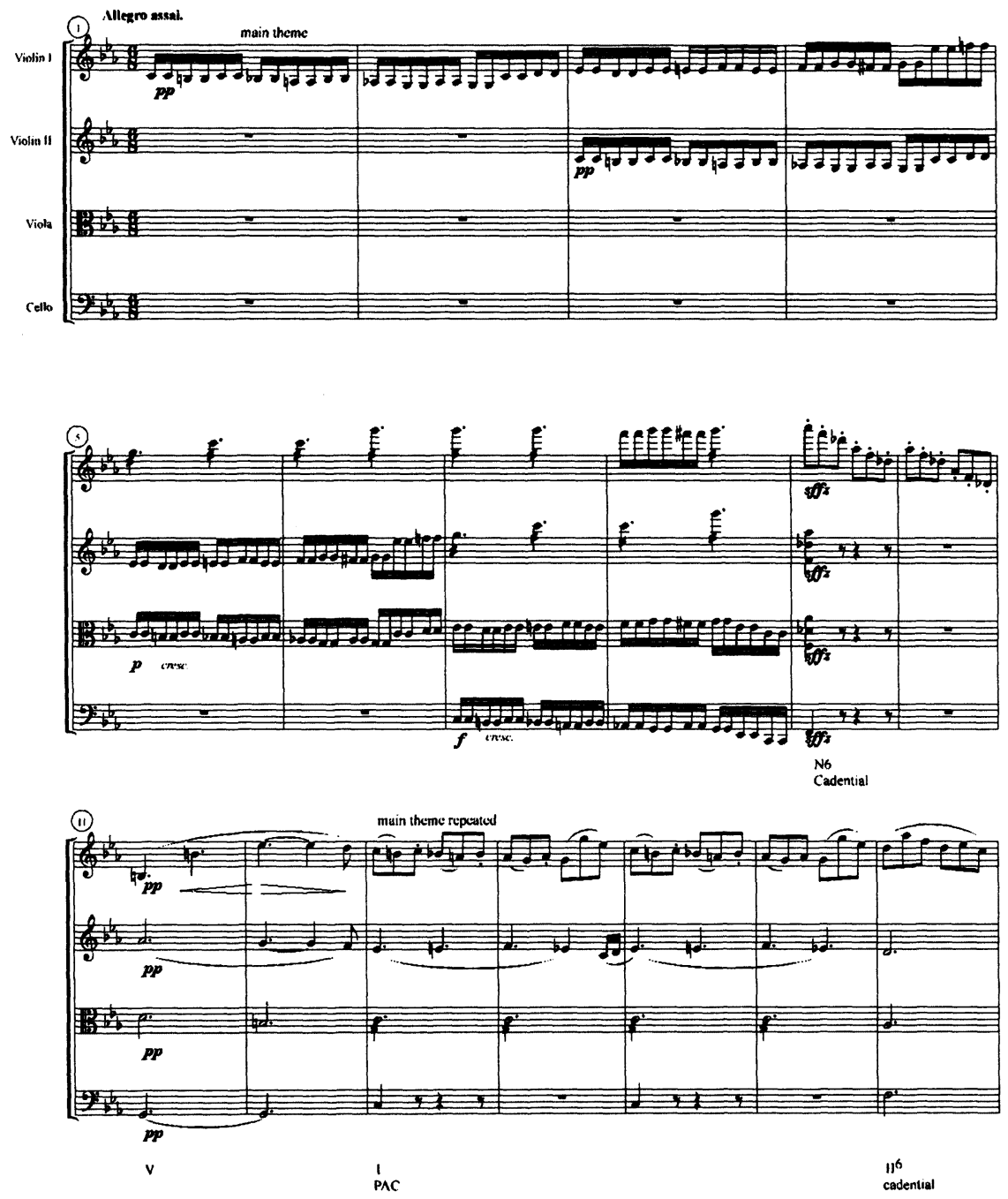

Example 8a. Quarettsatz in C minor, D. 703, main theme and transition to first subordinate theme

Neapolitan sixth. The F-G motion is reinforced in the listener's ear by the second cadence (bars 17-19), although the D-flat Neapolitan has been replaced here by a simple II6. In the third cadence, which accomplishes the transition's modulation (bars 23-27), the music returns to both the bass tone $\mathrm{F}$, and the D-flat Neapolitan sixth. However the F, instead of rising to $\mathrm{G}$ and the dominant chord of $\mathrm{C}$ minor, as it has twice before, now shifts downwards to another dominant, on E-flat, as the music pivots on the D-flat sixth chord 

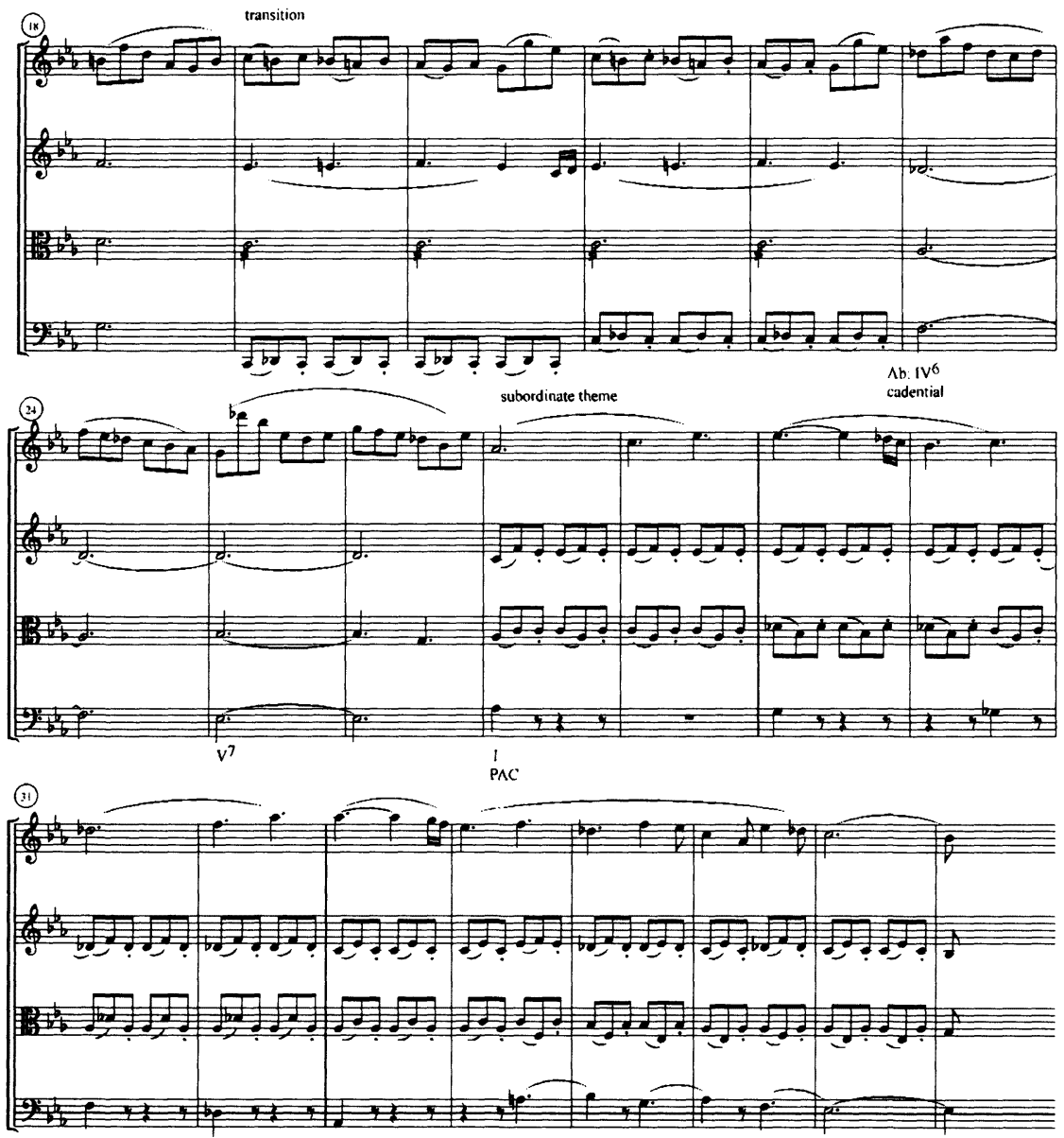

Example 8b. Quarettsatz in C minor, D. 703, main theme and transition to first subordinate theme

into a perfect authentic cadence in A-flat major. The slow harmonic rhythm at this point coupled with the wandering soprano line suggests the disorientation of someone overtaken by a vision.

The unusual character of the modulation heightens the difference between the two tonal realms to such an extent that it closes off one theme from the other in separate affective worlds. When recalled across this break, material from the main theme is mysteriously transfigured, as though seen through the aureole of a vision. This "estrangement of the familiar," so typical of a dream state, is particularly evident in the return of the two crucial sonorities of the movement's first cadence in C minor (example 8, bars 9-13). ${ }^{26}$ The 
first is the D-flat sixth chord. The second is more fluid in its definition, essentially consisting of the soprano E-flat against the bass $G$ (bar 12). In their first appearance as cadential harmonies in $C$ minor (bars 9-13), the two chords are imbued with a feeling of resignation, due to the tendency of the D-flat in the Neapolitan chord to fall to B-natural and the imperative of the E-flat, as a dissonance against the dominant chord, also to fall. When both are highlighted (in reverse order) in A-flat major at the beginning of the first subordinate theme (bars 29-34), their character is entirely transformed: as prominent participants in the melodic opening out of the first subordinate theme, they have acquired a freer, expansive quality. This is particularly audible in the new stability of the melodic E-flat as the root of a first inversion dominant seventh (bar 29).

The events of the transition set in motion a ripple effect in which certain sonorities involved in the modulation echo across the movement in memories of yearning. The first of these sonorities is the E-flat dominant seventh. In its dual nature, as both the dominant seventh of A-flat and the German sixth of G, it stands as the beginning and end points of two great spirals that encompass all tonal movement in the interior of the form. In the first spiral, the transition to the second subordinate theme, the music moves from A-flat, back through the original tonic $C$ minor, to return to the E-flat seventh (example 9). ${ }^{27}$ Now, though, this chord functions as the German sixth of $G$ in a passage preparing this new key through its dominant (bars 81-92). The chord's incorporation into a more conventional dominant preparation at this point suggests a return to "normalcy," as if the preceding modulation to A-flat major had been an illusory digression through a hidden aspect of the E-flat seventh chord.

The second spiral occupies the development section. Again the music moves from A-flat major, briefly through $\mathrm{C}$ to end in a dominant prolongation in $\mathrm{G}$ (example 10). The E-flat seventh frames the whole section, entering as the dominant seventh of A-flat major over an A-flat pedal (bar 143, not shown) and returning prominently as the German sixth of $G$ in the concluding dominant preparation (bars 181-94). G, however, never materializes as a tonality. At the point of arrival of the first subordinate theme (bar 195), the

central component of the cultivation of the mysterious in such E.T.A. Hoffmann tales as The Golden Pot, Princess Brambilla, Don Juan or The Chevalier von Gluck, where the natural world is often infected by the supernatural in such a way as to colour everyday objects with a new and uncanny meaning. This estrangement of the familiar is also central to an important project of Romantic poetry-the renewal of a freshness of vision. In the Preface to his Lyrical Ballades, for instance, Wordsworth proposes to choose in his poetry "incidents and situations from common life, and to relate or describe them ... in language really used by men; and at the same time to throw over them a certain colouring of imagination, whereby ordinary things should be presented to the mind in an unusual way ..." (my italics) (Wordsworth 1974a, 127).

27 As mentioned earlier, the return through the tonic on the way to the second subordinate key reinforces the suggestion that the first subordinate key and its theme are in some way an insubstantial vision. A-flat in particular takes on the position of a digressive tonal station on the way to the dominant, as if its whole thematic complex represented a fragile suspended world that inevitably must fade once the music resumes its course to the exposition's goal of the dominant. 

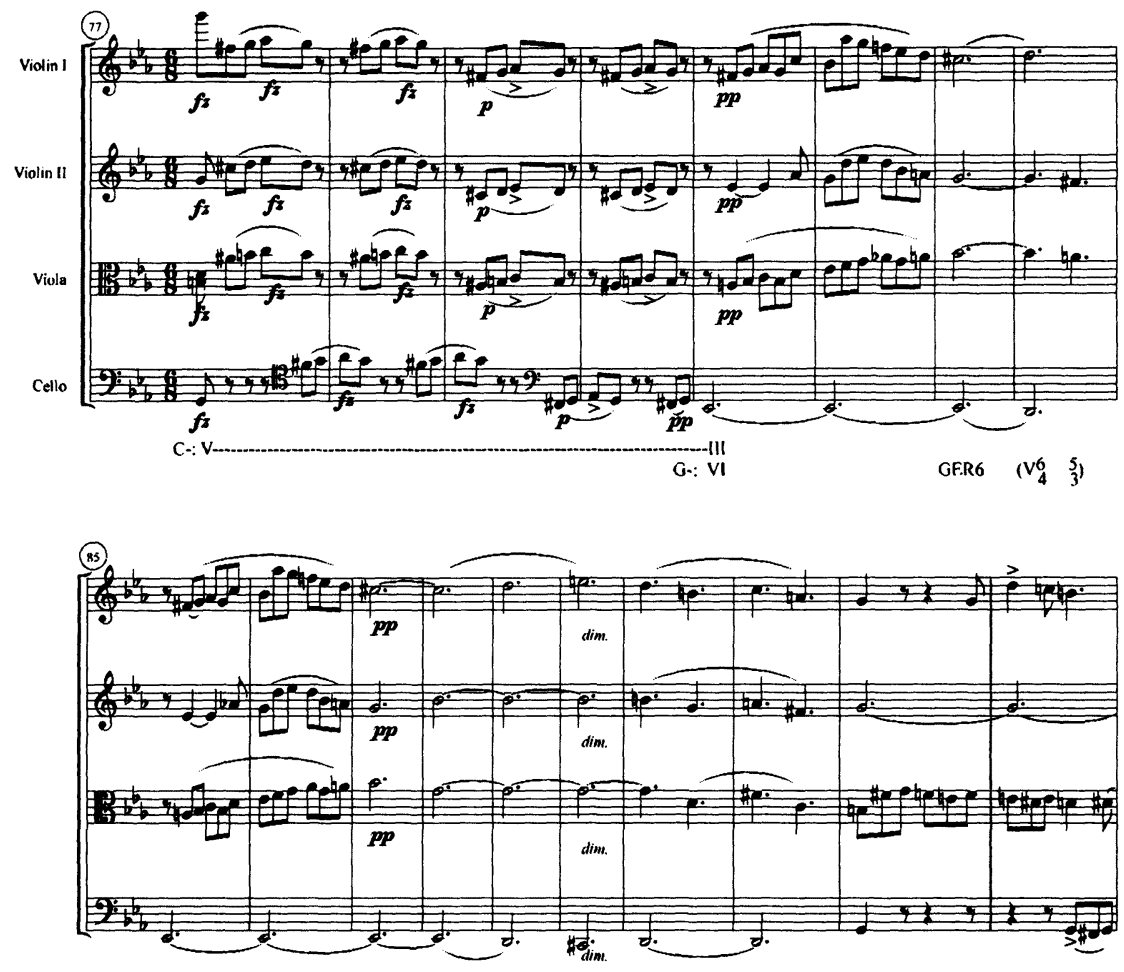
G: GER6

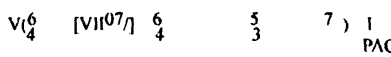

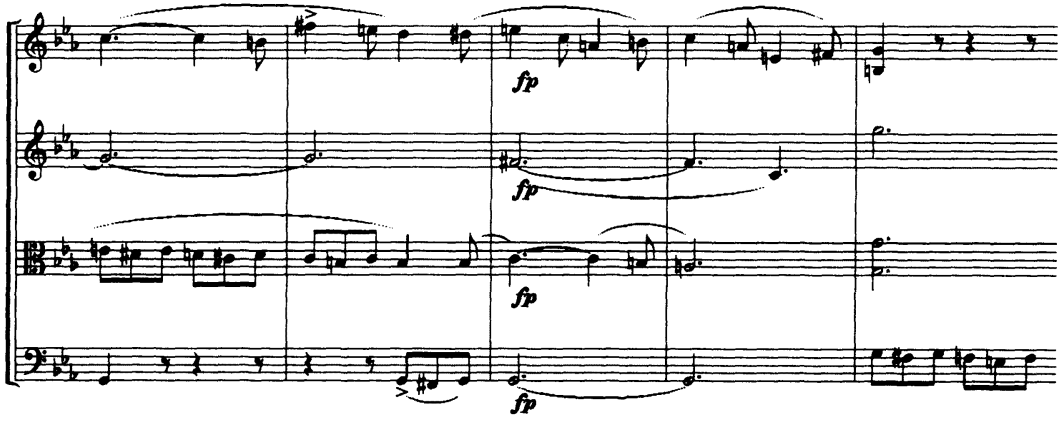

Example 9. Quarettsatz in C minor, D. 703, second transition 


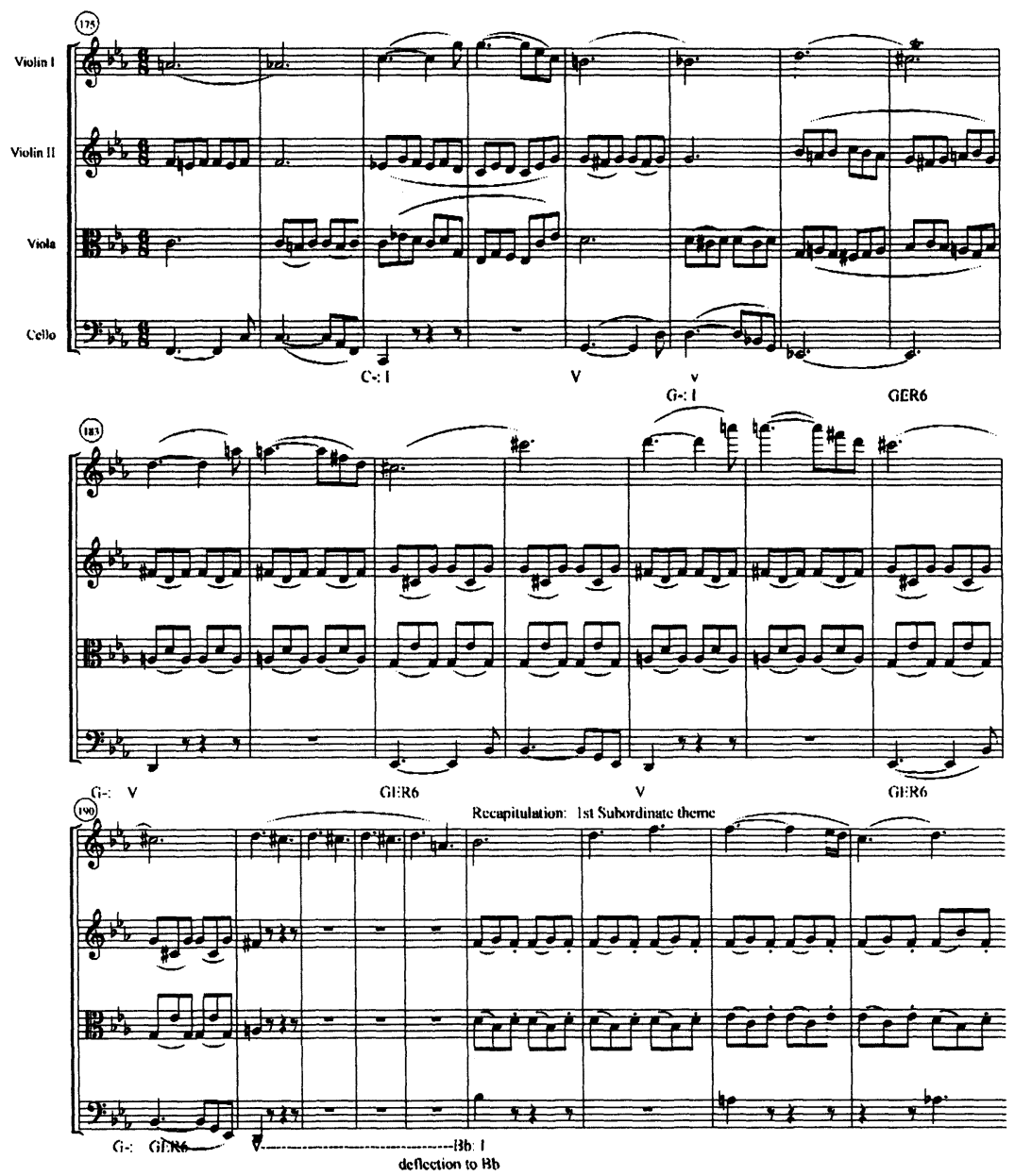

Example 10. Quarettsatz in C minor, D. 703, end of development section

music is suddenly deflected into B-flat major. ${ }^{28}$ The surprising shift intensifies the dream-like quality of the theme. Shortly afterwards, the unprepared key fades into E-flat major (bars 206-7, not shown). The insubstantial nature of B-flat major-its unexpected entrance and equally unexpected dissolution-suggests the immateriality of not just a dream, but the memory of a dream. The slip into E-flat major further intensifies the sense of yearning as the melodic arch expands, while the theme itself, by never being grounded in C, remains a vision forever floating outside the tonic sphere. ${ }^{29}$

28 Here Schubert uses the V/VI-I ploy mentioned in footnote 12.

29 I disagree with Hali Fieldman's contention that the E-flat region in some way acts as a tonic substitute into which the first subordinate theme is resolved (Fieldman, 2002). In the recapitulation, the first subordinate theme strongly cadences in E-flat major, after which a transition prepares the 
The circle of memory in the Quartettsatz extends even further with respect to the middle key of the exposition, A-flat major. Reminiscences of A-flat first resurface in the concluding cadences of the second subordinate theme. This thematic region is coloured by a strong sense of nostalgia, as it brings back fragments of both previous thematic worlds. ${ }^{30}$ In the concluding cadential area, a weird transformation of the main theme's descending tetrachord motive circling down $P P p$ in a descending whole tone sequence leads to an expanded A-flat Neapolitan chord, embellished by its E-flat dominant seventh. This occurs three times (example 11, bars 109, 117 and 121). The A-flat's return is cast as an explicit reminiscence of the vision of the first subordinate theme. The immediate focus of the melodic line, this chord appears in its more stable root position, while the sustained E-flat of the soprano voice suggests the rapt attention of someone lost in memory. In its third intrusion (bars 121-22), the vision dissolves as the Neapolitan sixth is absorbed into the concluding cadence in $\mathrm{G}$ major.

The A-flat chord returns prominently in the recapitulation at the end of the transition to the second subordinate theme (example 12). ${ }^{31}$ The way in which it is approached once more surrounds it with the aura of a vision. The transition moves to the dominant of F (IV, bars 241-44), then in a surprise that deliberately recalls the end of the development section, it suddenly shifts to the A-flat chord (bar 245). This chord in turn is converted into the German sixth of C (bar 247) as part of the dominant preparation of the tonic key (bars 245-56). Thus A-flat contains within itself both the dream and the seeds of the dream's destruction. In its expansion as a tonal region in the exposition it suggests the dream's idyll, the object of the dreamer's yearning. In its conversion to the German sixth here in the recapitulation it accomplishes the final return to the reality of the tonic key, C. (Illuminated by this event, the nostalgia of the ensuing second subordinate theme becomes all that more poignant.) The overarching circle of the music is then emphatically closed off by the sudden, brutal return of the main theme in $\mathrm{C}$ minor, which ends the movement with its beginning.

tonic major for the second subordinate theme, whose long concluding cadential passages are now grounded in the home key. Under such circumstances, it is very difficult to argue that the cadencing of the first subordinate theme outside the tonic is a stronger resolution of the tonal polarity set up in the exposition than the explicit grounding of the second subordinate theme in the tonic, whether it is in the major or minor mode.

30 This theme in fact assembles, in a fragile union, memories from the two previous thematic regions. Rhythmically, it recalls the smooth lyricism of the first subordinate theme, with which it also shares the same harmonic profile where the tonic is answered by the subdominant, rather than the dominant. (Compare bars 27-34 and bars 93-96). Beneath the melodic surface, though, lies the chromatic tetrachord of the main theme with the same uneasy feel to it (bars 93-96, viola and bars 99-102, cello), and this idea takes over as the main substance of the theme in the concluding cadential passages (bars 108-24). Furthermore the melody's dissonant D (bar94) and F-sharp (bar 96), each the highpoint of a three-note falling figure, add a bitter-sweet quality to the theme-a remembrance of the same dissonant melodic figure in the main theme's first cadence (bars 12-13, example 8), but now softened by the major mode and the melodic outline of the opening idea of first subordinate theme (bars 27-30, example 8).

$31 \mathrm{~A}$-flat has also been highlighted in the first subordinate theme of the recapitulation as the tonicized subdominant in E-flat major, bars 230-33. 

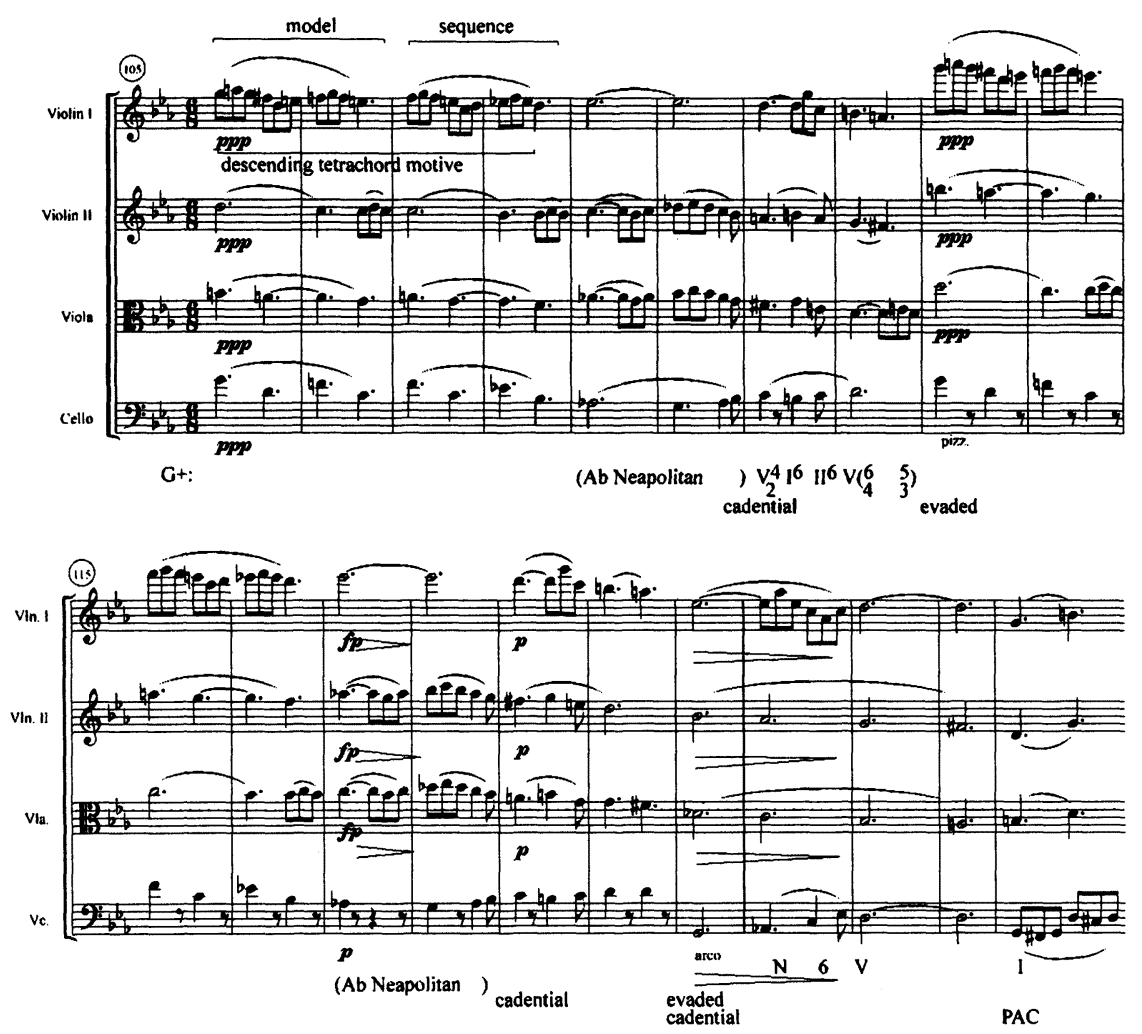

Example 11. Quarettsatz in C minor, D. 703, exposition, end of subordinate theme

\section{Schubert's Modulatory Process and the Spiral of REMEMBRANCE}

As we have seen in both the Quartettsatz and Nacht und Träume, the art of Schubert's modulatory process is one of illusion, in which the manipulation of enharmonic ambiguities and tonal expectations creates a sense of the otherworldly in his music, often suggesting the retreat into an interior dreamworld steeped in yearning. Musical elements other than the modulation itself also contribute to the illusive character of these visions. ${ }^{32}$ What is of fundamental importance, however, particularly in extensive instrumental forms, is the way in which Schubert pursues the implications of his tonal ploys across the form, so that the recurring intrusion of such visions becomes a central element of the broader design and meaning of the music. In such circum-

32 Among those aspects of Schubert's sonata forms that need to be discussed in relation to the illusory nature of his modulatory process is the particular character of the theme following the unusual modulation. Here specific features of the theme-its phrase structure, motivic construction, rhythmic profile and harmonic/tonal stability-would be crucial features to investigate on a case-by-case basis. 

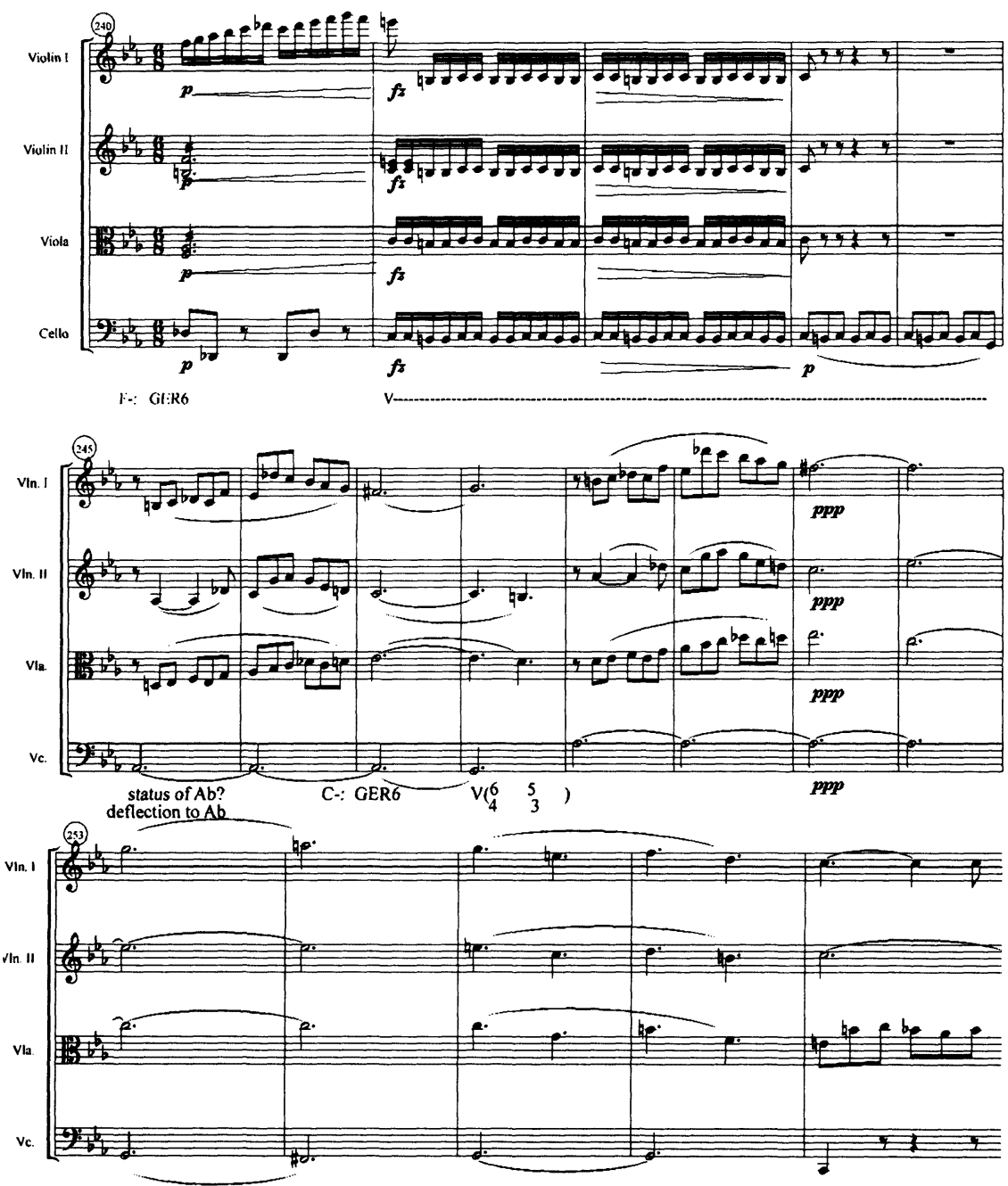

Example 12. Quarettsatz in C minor, D. 703, recapitulation, transition to second subordinate theme

stances, the array of different modulatory strategies Schubert uses allows for a subtle distinction between substantial and insubstantial states of existence, by either maintaining the otherworldly qualities of the modulation when the same theme returns later in the form, as in the unusual recapitulation of the Quartettsatz, or by contrasting that modulation with a carefully grounded, more conventional one, as in the Quartettsatz's second subordinate theme. Furthermore Schubert thoroughly integrates the illusory modulation into the form by having its constituent harmonic elements echo across the movement. The formal consequence of this type of construction, in which the structure of the movement is dominated by a circular tonal motion that flows outwards 
from the first modulation, merits a study in itself. The present article, though, has concentrated on the expressive effects of such forms, where the recall of subtly underscored sonorities in ever widening circles of reminiscence and regret brings into play the spiral of remembrance so central to the tragedy of Romantic memory and its yearning for "that which never was." 33 Thus, in its quiet mysteries and deep longing, Schubert's instrumental music speaks for an entire age by capturing both the intoxicating visions of early Romanticism and their bitter disappointments.

\section{REFERENCE LIST}

Abrams, M. H. 1971. Natural Supernaturalism: Tradition and Revolution in Romantic Literature. New York: W.W. Norton.

Beach, David. 1994. "Harmony and Linear Progression in Schubert's Music." Journal of Music Theory 38: 1-20.

Brown, Maurice J.E. 1980. The New Grove Schubert. New York: W.W. Norton. Burnham, Scott. 2000. "Schubert and the Sound of Memory." The Musical Quarterly 84: 655-63.

Burstein, Poundie. 2002. "Devil's Castles and Schubert's Strange Tonic Allusions." Theory and Practice 27: 69-84.

Caplin, William. 1998. Classical Form: A Theory of Formal Functions for the Instrumental Music of Haydn, Mozart, and Beethoven. New York: Oxford University Press.

Clark, Susannah. 2002. "Schubert, Theory and Analysis." Music Analysis 21: 209-43.

Coren, Daniel. 1970. “Ambiguity in Schubert's Recapitulations." Musical Quarterly 56: 779-93.

Daverio, John, "'One More Beautiful Memory of Schubert': Schumann's Critique of the Impromptus, D. 935." The Musical Quarterly 84: 604-18.

Fieldman, Hali. 2002. "Schubert's Quartettsatz and Sonata Form's New Way." Journal of Musicological Research 21: 99-146.

Fisk, Charles. 2000. "Schubert Recollects Himself: The Piano Sonata in C Minor, D.958." The Musical Quarterly 84: 635-54.

. 2001. Returning Cycles: Contexts for the Interpretation of Schubert's Impromptus and Last Sonatas. Berkeley: University of California Press.

Frisch, Walter. 2000. “'You Must Remember This': Memory and Structure in Schubert's String Quartet in G Major, D. 867." The Musical Quarterly 84: 582-603.

Gingerich, John. 2000. "Remembrance and Consciousness in Schubert's CMajor String Quintet, D. 956.” The Musical Quarterly 84: 619-34.

Hinrichsen, Hans Joachim. 1994. Untersuchungen zur Entwicklung der Sonatenform in der Instrumentalmusik Franz Schuberts. Tutzing: Hans Schneider.

33 This spiral of memory also infuses some of the composer's most tragic songs, such as the late masterpieces Die Stadt and Der Doppelgänger of Schwanengesang. 
Hoffmann, E.T.A.. 1971. "Review of the Fifth Symphony." In Beethoven: Symphony No. 5 in C minor. Elliot Forbes ed. 150-63. New York: W.W. Norton.

Kinderman, William. 1996. "Schubert's Tragic Perspective." In Schubert: Critical and Analytical Studies, Walter Frisch ed. 65-83. Lincoln: University of Nebraska Press.

Kopp, David. 2002. Chromatic Transformations in Nineteenth-Century Music. Cambridge: Cambridge University Press.

McClary, Susan. 1983. "Pitches, Expression, Ideology: An Exercise in Mediation." Enclitic 7: 76-86.

Newbould, Brian. 1997. Schubert: The Man and his Music. Berkeley: University of California Press.

Pesic, Peter. 1999. "Schubert's Dream." 19th-Century Music 23: 136-44.

Rönnau, Klaus. 1982. "Zu Tonarten-Disposition in Schuberts Reprisen." In Festschrift Heinz Becker, Jürgen Schläder and Reinholdt Quandt eds. 435-41. Laaber: Laaber Verlag.

Rosen, Charles. 1980. Sonata Forms. New York: W.W. Norton. . 1995. The Romantic Generation. Cambridge, Mass.: Harvard University Press.

Schachter, Carl. 1983. "Motive and Text in Four Schubert Songs." In Aspects of Schenkerian Theory, David Beach ed. 61-76. New Haven: Yale University Press.

Webster, James. 1978. "Schubert's Sonata Form and Brahms's First Maturity, I." $19^{\text {th }}$-Century Music 3: 18-35.

Wordsworth, William. 1974a. Preface to Lyrical Ballads, with Pastoral and Other Poems. The Norton Anthology of English Literature, vol. 2, M.H. Abrams ed. New York: W.W. Norton, 124-40.

. 1974b. "Ode: Intimations of Immortality." The Norton Anthology of English Literature, vol. 2, M.H. Abrams ed. New York: W.W. Norton, 175-81.

\section{ABSTRACT}

The idea of the dream as a longed-for alternative to reality imbues many of Schubert's finest sonata forms with what Charles Rosen has isolated as the tragedy of Romantic memory, the yearning for "that which never was." Here the unusual methods Schubert uses to modulate in his transitions create a sense of something alluring, yet insubstantial, in the subordinate key/theme, an effect that is maintained across the movement, whose progress thus ultimately suggests the tragic pursuit of an illusion.

\section{RESUME}

L'idée du rêve comme besoin alternatif à la réalité imprègne plusieurs des sonates de Schubert. Ce "désir de ce qui n'a jamais été " constitue ce que Charles Rosen a identifié comme le tragique de la mémoire romantique. D'où 
les méthodes particulières de modulation utilisées par Schubert dans ses transitions, qui créent une impression séduisante, quoique évanescente dans le rapport tonalité/thème, un effet maintenu tout au long du mouvement, dont la progression suggère, en dernière analyse, la poursuite tragique d'une illusion. 